\title{
Prolonged survival of patients with angioimmunoblastic T-cell lymphoma after high-dose chemotherapy and autologous stem cell transplantation. The GELTAMO experience
}

José Rodríguez ${ }^{1}$, Eulogio Conde ${ }^{2}$, Antonio Gutiérrez ${ }^{1}$, Reyes Arranz ${ }^{3}$, Marcos Gandarillas ${ }^{2}$, Angel Leon ${ }^{4}$, Jesus Ojanguren ${ }^{5}$, Anna Sureda ${ }^{6}$, Dolores Carrera ${ }^{7}$, Mauricio Bendandi ${ }^{8}$, Jose Moraleda ${ }^{9}$, Jose Maria Ribera ${ }^{10}$, Carmen Albo ${ }^{11}$, Alfonso Morales ${ }^{12}$, Juan Carlos García ${ }^{13}$, Pascual Fernández ${ }^{14}$, Guillermo Cañigral ${ }^{15}$, Juan Bergua ${ }^{16}$, María Dolores Caballero ${ }^{17}$, On behalf of the Grupo Español de Linfomas/Trasplante Autólogo de Médula Ósea (GEL-TAMO - Spanish Iymphoma/autologous bone marrow transplant study group)

\footnotetext{
${ }^{1}$ Hospital Universitario Son Dureta, Palma; ${ }^{2}$ Hospital Valdecilla, Santander; ${ }^{3}$ Hospital La Princesa, Madrid; ${ }^{4}$ Hospital Jerez de la Frontera; ${ }^{5}$ Hospital Galdakao, Vizcaya; ${ }^{6}$ Hospital Sant Pau, Barcelona; ${ }^{7}$ Hospital Central de Asturias, Oviedo; ${ }^{8}$ Clínica de Navarra, Pamplona; ${ }^{9}$ Hospital Morales Meseguer, Murcia; ${ }^{10}$ Hospital Germans Trias i Pujol, Barcelona; ${ }^{11}$ Hospital Xeral-Cíes, Pontevedra; ${ }^{12}$ Hospital Universitario 'Virgen de La Arrixaca'; ${ }^{13}$ Hospital de Cruces, Vizcaya; ${ }^{14}$ Hospital General de Alicante; ${ }^{15}$ Hospital General de Castellón; ${ }^{16}$ Hospital San Pedro de Alcántara, Cáceres;

${ }^{17}$ Hospital Clínico, Salamanca, Spain
}

\begin{abstract}
Objectives: Angioimmunoblastic T-cell lymphoma (AIL) is a rare lymphoma with a poor prognosis and no standard treatment. Here, we report our experiences with 19 patients treated with high-dose chemotherapy and autologous stem cell transplantation (HDC/ASCT) within the GELTAMO co-operative group between 1992 and 2004. Methods: The median age at transplantation was 46 yr. Fifteen patients underwent the procedure as front-line therapy and four patients as salvage therapy. Most patients received peripheral stem cells $(90 \%)$ coupled with BEAM or BEAC as conditioning regimen (79\%). Results: A $79 \%$ of patients achieved complete response, $5 \%$ partial response and $16 \%$ failed the procedure. After a median follow-up of 25 months, eight patients died (seven of progressive disease and secondary neoplasia), while actuarial overall survival and progression-free survival at 3 yr was $60 \%$ and $55 \%$. Prognostic factors associated with a poor outcome included bone marrow involvement, transplantation in refractory disease state, attributing more than one factor of the age-adjusted-International Prognostic Index, Pretransplant peripheral T-cell lymphoma (PTCL) Score or Prognostic Index for PTCL. Conclusions: More than half of the patients with AIL that display unfavourable prognostic factors at diagnosis or relapse would be expected to be alive and disease-free after $3 \mathrm{yr}$ when treated with HDC/ASCT. Patients who are transplanted in a refractory disease state do not benefit from this procedure.
\end{abstract}

Key words angioimmunoblastic T-cell lymphoma; autologous transplantation

Correspondence Dr José Rodríguez, Servicio de Oncología, Hospital Son Dureta, Av. Andrea Doria 55, Palma de Mallorca 07014, Spain. Tel.: +34 971 175000; Fax: +34 971 175500; e-mail: jrodriguez@hsd.es

Accepted for publication 12 December 2006

doi:10.1111/j.1600-0609.2007.00815.x

Angioimmunoblastic T-cell lymphoma (AIL) is a rare Tcell malignancy with characteristic clinical and morphological features (1-3). Although it was originally thought to be a relatively benign disorder and was classified as a low-grade lymphoma, it is currently classified by the WHO as a discrete entity representing around $20 \%$ of aggressive T-cell lymphomas. This lymphoma mainly affects elderly people who present an array of characteristic signs and symptoms including disseminated lymphadenopathy, constitutional symptoms, as well as known haematological abnormalities (4).

No standard treatment for this aggressive disease has yet been defined, in part due to the relative rarity of the disease. Given the typical relationship of this lymphoma 
with autoimmune phenomena, immunomodulators such as interferon (5-7) or other immunosuppressor drugs such as cyclosporine $(8,9)$ and corticoids $(10,11)$ have been reported to be active against the disease in simple case reports or in very small series. Indeed, the vast majority of reports dealing with this condition are simple case reports treated with single agents or conventional chemotherapy regimes typically used against aggressive lymphomas. However, taking into account the dismal prognosis of the disease, conventional chemotherapy regimes have been tested, generally with unsatisfactory results (11-18).

Following initial reports of the favourable impact of high dose chemotherapy/autologous stem cell therapy (HDC/ASCT), the European Group for Bone Marrow Transplantation (EBMT) reported a 5-yr event-free survival (EFS) of $37 \%$ and an overall survival (OS) of $44 \%$ at $5 \mathrm{yr}$ in 29 patients, of whom 14 underwent transplantation as a first line therapy (19). As a further contribution to redress the lack of data regarding therapeutic measures for this condition, we report here our experiences with 19 patients treated with HDC/ASCT within the GELTAMO Spanish lymphoma group.

\section{Patients and methods}

\section{Patients}

Between 1992 and 2004, 19 patients with AIL who underwent HDC/ASCT were reported to the GELTAMO registry. The clinical characteristics of the patients at diagnosis are shown in Table 1 . The median age at transplantation was $46 \mathrm{yr}$, and 15 patients were transplanted as front line therapy having been judged by their primary physician to have high risk factors of failure. Of these 15 patients, eight were transplanted as a consolidation of the first complete response (CR), five patients were transplanted in the first partial response (PR), and two patients were transplanted in a primary refractory disease state. Four patients received the transplant as a salvage therapy, of which three patients were in a second or third CR phase and one patient in the second PR (Table 2).

Standard criteria to determine eligibility for therapy were applied including: bilirubin levels $<2 \mathrm{mg} / \mathrm{dL}$; creatinine levels $<1.5 \mathrm{mg} / \mathrm{dL}$; an ejection fraction $>50 \%$; and appropriate diffusing lung tests $>50 \%$ of the predictive value. Histological diagnosis was established by the pathologist in each centre. Cases that displayed difficult diagnostic features were referred to an expert haematopathologist following the recommendations of the group.

The disease stage was evaluated according to the Ann Arbour staging system and patients were staged according to standard procedures through: physical examination; blood and serum assays; chest X-rays; and
Table 1 Clinical characteristics of patients at diagnosis and transplant

\begin{tabular}{lll}
\hline Variable & At diagnosis & At transplant \\
\hline Age, mean (range) & $10(53) / 9(47)$ & $46(16-65)$ \\
Sex (M/F) & $16(84)$ & $4(21)$ \\
Ann Arbour Stage III-IV & $14(74)$ & $1(5)$ \\
B-symptoms & $3(16)$ & $0(0)$ \\
$>1$ extranodal sites & $5(26)$ & $3(16)$ \\
BM involvement & $3(16)$ & $0(0)$ \\
Bulky disease & $10(53)$ & $2(10)$ \\
ECOG PS $>1$ & $10(53)$ & $4(21)$ \\
High LDH & $7(50)$ & $6(43)$ \\
High $\beta 2$ M & $12(63)$ & $2(10)$ \\
Age-adjusted-IPI 2-3 & $10(56)$ & $2(12)$ \\
Tumour score 3-5 & - & $5(38)$ \\
PPS 2-3 & $11(61)$ & $3(17)$ \\
PIT >1 & & \\
Pretransplant regimes & $9(47)$ & \\
CHOP & $7(37)$ & \\
MegaCHOP & $2(10)$ & \\
MACOP-B & $1(5)$ & \\
PromaceCytabon & $15(79)$ & \\
Treatment lines pretransplant & $2(10)$ & \\
First-line & $2(10)$ & \\
Second-line & & \\
Third-line & & \\
\hline BM & &
\end{tabular}

BM, bone marrow; ECOG PS, Eastern Cooperative Oncology Group Performance Status; LDH, lactate dehydrogenase; $\beta 2 \mathrm{M}$, beta-2-microglobuline; IPI, International Prognostic Index; PPS, Pretransplant Peripheral T-cell lymphoma Score; PIT, Prognostic Index for peripheral T-cell lymphoma.

Values in parenthesis are in percentage.

Table 2 Transplant-related factors

\begin{tabular}{lc}
\hline Median months to transplant (range) & $9(4-51)$ \\
Disease status & \\
First CR & $8(42)$ \\
Second or more CR & $3(16)$ \\
First PR & $5(26)$ \\
Second or more PR & $1(5)$ \\
Refractory & $2(10)$ \\
Conditioning regimens & \\
BEAM & $12(63)$ \\
BEAC & $3(16)$ \\
Cy plus TBI & $2(10)$ \\
CVB & $2(10)$ \\
Stem cell source & \\
BM & $1(5)$ \\
PB & $18(95)$ \\
Median apheresis (range) & $3(1-6)$ \\
Treatment-related mortality & $0(0)$ \\
Engraftment & $19(100)$ \\
\hline
\end{tabular}

$\mathrm{CR}$, complete response; $\mathrm{PR}$, partial response; $\mathrm{BM}$, bone marrow; $\mathrm{PB}$, peripheral blood.

Values in parenthesis are in percentage.

computed tomography of the neck, chest, abdomen and pelvis. Bone marrow aspirates and biopsies were obtained prior to HDC and other staging criteria were assessed at 
diagnosis to define the pretransplantation condition. Standard variables of the age-adjusted International Prognostic Index (a-IPI) (20) and other variables of known prognostic importance in this type of lymphomas were also evaluated (21-23). The details and factors associated with transplantation are provided in Table 2.

\section{Response and follow-up criteria}

The response to therapy was evaluated by the investigator responsible in each centre at 1, 3 and 6 months post-transplantation, and every 6 months thereafter. Evaluations followed standard guidelines (24), carrying out a physical examination, complete blood counts, serum biochemistry, bone marrow aspiration and biopsy, and radiological studies as mentioned above. CR was defined as the disappearance of all clinical evidence of lymphoma for a minimum of $4 \mathrm{wk}$ with no persistence of symptoms related to the disease. Prior to transplantation, a complete restaging was established in all patients. To categorize a patient with a $\mathrm{CR}$ after $\mathrm{HDC} / \mathrm{ASCT}$, residual masses had to remain unchanged for 6 months or longer. A PR was defined as a decrease of more than $50 \%$ in the sum of the two longest diameters of all measurable lesions over at least $4 \mathrm{wk}$ and non-measurable lesions had to decrease by at least $50 \%$. In this category, no lesions increased in size and no new lesions appeared. Progressive disease (PD) was defined as any increase of more than $25 \%$ in the sum of the diameter of any measurable lesions or the appearance of a new lesion. Transplant-related mortality (TRM) was defined as death within $100 \mathrm{~d}$ of HDC/ASCT not related to the disease, relapse or progression. Toxic mortality was considered at any time, if it was related to the therapeutic procedure.

\section{Statistical methods}

Progression-free survival (PFS) and OS were measured from the date of transplantation and were estimated according to the Kaplan-Meier method (25). Comparisons amongst the variables of interest were performed by the log-rank test (26). All $P$-values reported were twosided and the statistical significance was defined at a $P$-value $<0.05$.

\section{Results}

\section{Outcome}

Post-transplantation, $79 \%$ of the whole population could be considered to have achieved a CR $(n=15)$, while $5 \%$ of patients displayed a $\operatorname{PR}(n=1)$ and the procedure failed in $16 \%$ ( $n=3$, including the two cases transplanted in a refractory disease state). Table 3 shows response
Table 3 Response to transplant

\begin{tabular}{llrr}
\hline & \multicolumn{3}{l}{ Response to transplant } \\
\cline { 2 - 4 } Disease status at transplant & CR & PR & Refractory \\
\hline First CR & $8(100)$ & 0 & 0 \\
Second or more CR & $3(100)$ & 0 & 0 \\
First PR & $4(80)$ & 0 & $1(20)$ \\
Second or more PR & 0 & $1(100)$ & 0 \\
Refractory & 0 & 0 & $2(100)$ \\
\hline
\end{tabular}

CR, complete response; PR, partial response.

Values in parenthesis are in percentage.
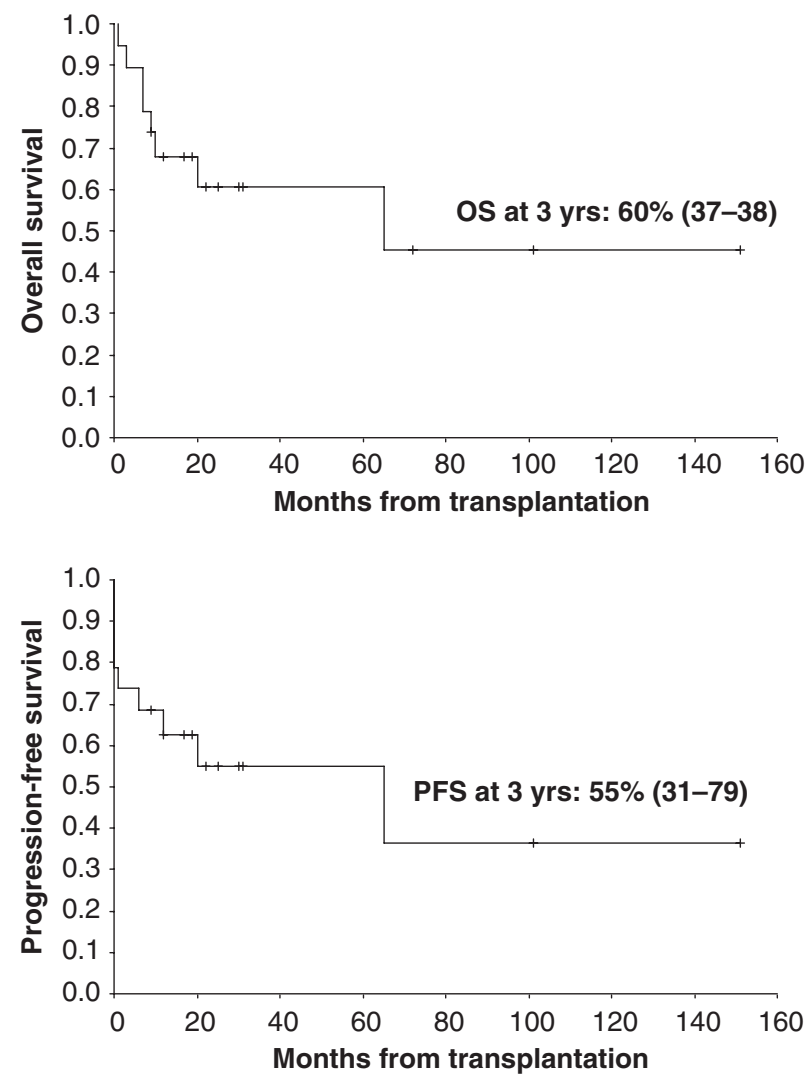

Figure 1 Overall survival and progression-free survival.

to transplant considering the disease status before transplant. With a median observation time in living patients of 25 months (9-151), the OS at 3 yr was $60 \%(95 \% \mathrm{CI}$ : 37-83) and the PFS was 55\% (95\%, CI: 31-79; Fig. 1). To date, eight patients had died, seven of them due to the disease and one patient from a second neoplasia (MDS). There were no incidences of TRM or toxic deaths related to procedure.

\section{Prognostic factors}

Despite being a small group of patients, we performed a univariate analysis to determine which clinical factors 
might be associated with the outcome. The group of eight patients transplanted in the first CR had an OS and PFS at $3 \mathrm{yr}$ of $56 \%$. Similarly, no differences were observed in the OS or PFS at $3 \mathrm{yr}$ amongst the group of 15 patients transplanted as a front line therapy when compared with the four patients who were transplanted at relapse $(67 \%$ vs. $50 \%, P=0.29$ and $59 \%$ vs. $50 \%$, $P=0.57$ respectively). However, the refractory disease state at transplantation that was observed in two patients, predicted a dismal prognosis as both these patients died from the disease shortly after the procedure (within 1 and 3 months). Likewise, patients with extranodal disease at the time of transplantation and with bone marrow involvement were associated with a poor outcome. Between the prognostic indexes studied the outcome was significantly associated with the a-IPI, Pretransplant Peripheral T-cell lymphoma Score (PPS) (23) and Prognostic Index for peripheral T-cell lymphoma (PIT) (22) (Table 4, Fig. 2).

\section{Discussion}

AIL is a rare disease with a poor prognosis. With the therapeutic strategies currently available, a median survival of 18-36 months has been observed when conventional chemotherapy was applied in most series $(4,12)$. There is a lack of informative series of patients that have been treated uniformly and indeed, most reports include single patients or very small groups of patients. Therefore, it is difficult to draw firm conclusions from the information obtained to date. Recently, the EBMT reported their experiences with 29 patients diagnosed with this disease and subjected to HDC/ASCT. Half of the patients received the transplant as part of a first-line therapy and half as second or third line therapy (19). This group reported a CR of $76 \%$ after HDC/ASCT, which is similar to the CR in our series $(79 \%)$. Along similar lines, the 5-yr OS and PFS were $44 \%$ and $37 \%$ respectively, inferior to our $60 \%$ and $55 \%$ OS and PFS at $3-5 \mathrm{yr}$ respectively. However, this may reflect the fact that most of our patients $(79 \%)$ were transplanted as a first line treatment as opposed to $45 \%$ in the EBMT series. Furthermore, our median observation period of 25 months for surviving patients is shorter than the 60 months in the EBMT series.

Our analysis showed that like patients with other aggressive Peripheral T-cell lymphoma (PTCL), those transplanted in a refractory disease state do poorly with HDC/ASCT (27-29). In addition, we found that the presence of extranodal disease (bone marrow) or more than one adverse factor at transplant of those assessed in the a-IPI, PPS or PIT scores was associated with a worse outcome. Although studied in few patients, this information suggests that HDC/ASCT improves the outcome of
Table 4 Prognostic factors at transplant

\begin{tabular}{|c|c|c|c|c|}
\hline Parameter & $\begin{array}{l}\text { OS at } 3 \mathrm{yr}, \% \\
(95 \% \mathrm{Cl})\end{array}$ & $P$-value & $\begin{array}{l}\text { PFS at } 3 \mathrm{yr}, \% \\
(95 \% \mathrm{Cl})\end{array}$ & $P$-value \\
\hline \multicolumn{5}{|l|}{ Status at transplant } \\
\hline $\mathrm{CR}$ & 65 (31-99) & \multirow[t]{2}{*}{$<0.001$} & 65 (31-99) & \multirow[t]{3}{*}{0.011} \\
\hline$P R$ & $67(29-100)$ & & $50(10-90)$ & \\
\hline Refractory disease & 0 & & 0 & \\
\hline \multicolumn{5}{|l|}{ Extranodal disease } \\
\hline No & $69(44-95)$ & \multirow[t]{2}{*}{0.049} & $62(35-89)$ & \multirow[t]{2}{*}{ NS } \\
\hline Yes & $25(0-67)$ & & $25(0-67)$ & \\
\hline \multicolumn{5}{|l|}{ BM involvement } \\
\hline No & 72 (48-96) & \multirow[t]{2}{*}{$<0.001$} & $65(40-91)$ & \multirow[t]{2}{*}{$<0.001$} \\
\hline Yes & 0 & & 0 & \\
\hline \multicolumn{5}{|l|}{ Age-adjusted-|PI } \\
\hline 0 or 1 & $68(44-92)$ & \multirow[t]{2}{*}{$<0.001$} & $61(36-86)$ & \multirow[t]{2}{*}{0.005} \\
\hline More than 1 & 0 & & 0 & \\
\hline \multicolumn{5}{|l|}{ PPS } \\
\hline 0 & $75(45-100)$ & \multirow[t]{3}{*}{0.001} & 62 (29-95) & \multirow[t]{3}{*}{ NS } \\
\hline 1 & $50(1-99)$ & & $50(1-99)$ & \\
\hline 2 & 0 & & 0 & \\
\hline \multicolumn{5}{|l|}{$\mathrm{PIT}$} \\
\hline 0 or 1 & $64(38-90)$ & \multirow[t]{2}{*}{0.019} & $57(30-84)$ & \multirow[t]{2}{*}{ NS } \\
\hline More than 1 & $33(0-86)$ & & $33(0-86)$ & \\
\hline \multicolumn{5}{|l|}{ Tumour score } \\
\hline $0-2$ & 65 (39-91) & \multirow[t]{2}{*}{ NS } & $57(21-84)$ & \multirow[t]{2}{*}{ NS } \\
\hline $3-5$ & $50(0-100)$ & & $50(0-100)$ & \\
\hline \multicolumn{5}{|l|}{ Age $>60 \mathrm{yr}$} \\
\hline No & 62 (38-86) & \multirow[t]{2}{*}{ NS } & $56(31-80)$ & \multirow[t]{2}{*}{ NS } \\
\hline Yes & $67(13-100)$ & & $67(13-100)$ & \\
\hline \multicolumn{5}{|l|}{ Ann Arbour Stage } \\
\hline No disease & - & NS & 65 (31-99) & NS \\
\hline$|-| \mid$ & $75(33-100)$ & & $50(1-99)$ & \\
\hline III-IV & $25(0-67)$ & & $25(0-67)$ & \\
\hline ECOG PS $>1$ & & & & \\
\hline No & $61(36-86)$ & NS & $55(29-81)$ & NS \\
\hline Yes & $50(0-100)$ & & $50(0-100)$ & \\
\hline High LDH & & & & \\
\hline No & 61 (33-88) & NS & $53(24-81)$ & NS \\
\hline Yes & $50(1-99)$ & & $50(1-99)$ & \\
\hline High $\beta 2 \mathrm{M}$ & & & & \\
\hline No & $75(45-100)$ & NS & 62 (19-96) & NS \\
\hline Yes & $44(1-88)$ & & $44(1-88)$ & \\
\hline Induction regime & & & & \\
\hline $\mathrm{CHOP}$ & $65(32-97)$ & NS & 67 (36-97) & NS \\
\hline MegaCHOP & 54 (14-93) & & 54 (14-93) & \\
\hline
\end{tabular}

OS, overall survival; PFS, progression-free survival; $\mathrm{Cl}$, confidence interval; $\mathrm{CR}$, complete response; $\mathrm{PR}$, partial response; $\mathrm{BM}$, bone marrow; IPI, International Prognostic Index; PPS, Pretransplant Peripheral T-cell lymphoma Score; PIT, Prognostic Index for peripheral T-cell lymphoma; ECOG PS, Eastern Cooperative Oncology Group Performance Status; LDH, lactate dehydrogenase; $\beta 2 \mathrm{M}$, beta-2-microglobuline; NS, not significant.

the disease when compared with conventional treatment, indicating that prospective studies to test this therapeutic modality are necessary. Moreover, the use of this therapy is limited in the elderly population. Therefore, taking into account the biological phenomena associated with 

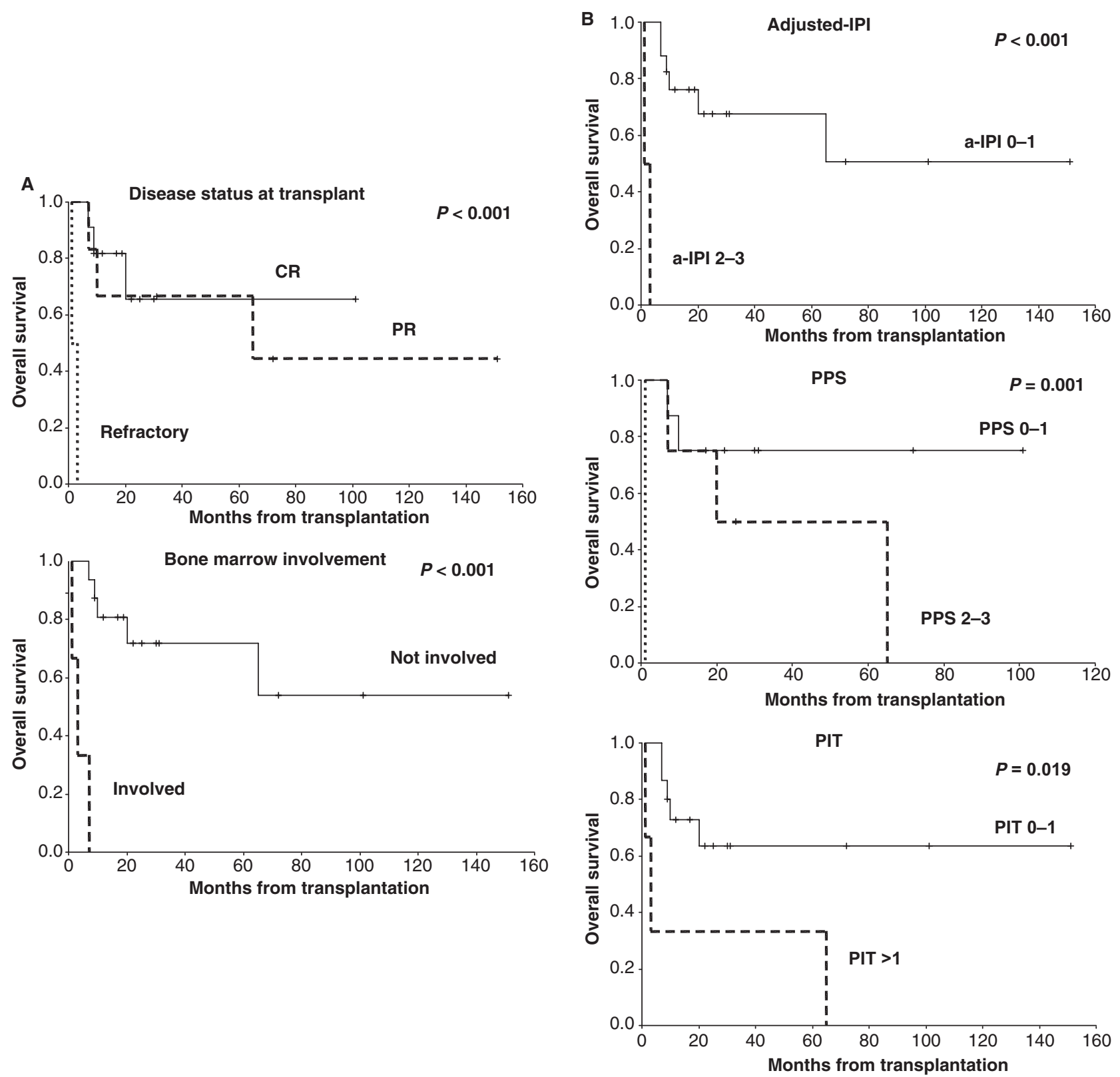

Figure 2 Prognostic factors associated with overall survival. A) Significant adverse prognostic factors. B) Significant prognostic scores.

the disease, novel more specific therapies will be needed and other potential targets must be defined. Interestingly, immunomodulatory and antiangiogenic agents have been reported to have positive impact on the disease (IFN $\alpha$, IL-2, Thalidomide...), however the real impact of these agents remains unknown due to the small number of patients studied $(4,30)$.

Another intriguing approach that involves targeting the B-cell component rather than the malignant $\mathrm{T}$-cell population is currently being tested (31). Indeed, this Bcell component is responsible for several features of the disease and it is argued that it may contribute to sustain the malignant $\mathrm{T}$ cells. Along similar lines, there are several reports outlining the responses to Rituximab in treating this disease. Furthermore, a certain efficacy has also been reported with Campath-1H in single case reports (32). Thus, new biological agents, used either individually or in combination with conventional chemotherapy may have an impact on the disease. However, as suggested by our data and that of others ASCT, may represent the best available consolidation therapy for patients that comply with certain criteria.

In conclusion, our data show that HDC/ASCT offers better results than conventional chemotherapy in treating 
aggressive lymphomas. Although further follow-up is needed to confirm these results, more than half of the patients in this study were in continued remission. However, we identified several factors such as refractory disease state, extranodal disease (bone marrow involvement) and the presence of more than one adverse factor from the a-IPI, PPS or PIT pretransplantation scores that are unfavourable factors associated with a poor outcome of this therapeutic modality. New target therapies drawn from genomic and proteomic studies should be defined in order to develop more specific therapies. Moreover, due to the rarity of the disease, cooperative efforts and well-designed prospective studies are needed in order to reach meaningful conclusions.

\section{References}

1. World Health Organization Classification of Tumours. Pathology and Genetics of Tumours of Hematopoietic and Lymphoid Tissues. Lyon: IARC Press, 2001.

2. Harris NL, Jaffe ES, Stein H, et al. A revised EuropeanAmerican classification of lymphoid neoplasms: a proposal from the International Lymphoma Study Group.

Blood 1994;84:1361-92.

3. Rudiger T, Weisenburger DD, Anderson JR, et al. Peripheral T-cell lymphoma (excluding anaplastic large-cell lymphoma): results from the Non-Hodgkin's Lymphoma Classification Project. Ann Oncol 2002;13:140-9.

4. Siegert W, Nerl C, Agthe A, et al. Angioimmunoblastic lymphadenopathy (AILD)-type T-cell lymphoma: prognostic impact of clinical observations and laboratory findings at presentation. The Kiel Lymphoma Study Group. Ann Oncol 1995;6:659-64.

5. Feremans WW, Khodadadi E. Alpha-interferon therapy in refractory angioimmunoblastic lymphadenopathy. Eur $J$ Haematol 1987;39:91.

6. Hast R, Gustafsson B. Improved response to chemotherapy after interferon alpha-2b in angioimmunoblastic lymphadenopathy (AILD). Eur J Haematol 1991;46:51-2.

7. Siegert W, Nerl C, Meuthen I, et al. Recombinant human interferon-alpha in the treatment of angioimmunoblastic lymphadenopathy: results in 12 patients. Leukemia 1991;5:892-5.

8. Advani R, Warnke R, Sikic BI, Horning S. Treatment of angioimmunoblastic T-cell lymphoma with cyclosporine. Ann Oncol 1997;8:601-3.

9. Murayama T, Imoto S, Takahashi T, Ito M, Matozaki S, Nakagawa T. Successful treatment of angioimmunoblastic lymphadenopathy with dysproteinemia with cyclosporin A. Cancer 1992;69:2567-70.

10. Colbert N, Andrieu JM, Bernard J. Pulse methylprednisolone therapy in angioimmunoblastic lymphadenopathy. Acta Haematol 1982;68:307-8.

11. Siegert W, Agthe A, Griesser H, et al. Treatment of angioimmunoblastic lymphadenopathy (AILD)-type T-cell lymphoma using prednisone with or without the COPBLAM/IMVP-16 regimen. A multicenter study. Kiel Lymphoma Study Group. Ann Intern Med 1992;117:36470.

12. Pautier P, Devidas A, Delmer A, et al. Angioimmunoblastic-like T-cell non Hodgkin's lymphoma: outcome after chemotherapy in 33 patients and review of the literature. Leuk Lymphoma 1999;32:545-52.

13. Awidi AS, Tarawneh MS, Abu Khalaf MS, Al Khateeb MS, Amr SS. Therapeutic effect of vincristine, adriamycin and prednisolone (VAP) in angioimmunoblastic lymphadenopathy (AIL). Cancer Chemother Pharmacol 1983;10:221-2.

14. Quintini G, Iannitto E, Barbera V, et al. Response to lowdose oral methotrexate and prednisone in two patients with angio-immunoblastic lymphadenopathy-type T-cell lymphoma. Hematol J 2001;2:393-5.

15. Gerlando Q, Barbera V, Ammatuna E, Franco V, Florena AM, Mariani G. Successful treatment of angioimmunoblastic lymphadenopathy with dysproteinemia-type T-cell lymphoma by combined methotrexate and prednisone. Haematologica 2000;85:880-1.

16. Sallah AS, Bernard S. Treatment of angioimmunoblastic lymphadenopathy with dysproteinemia using 2-chlorodeoxyadenosine. Ann Hematol 1996;73:295-6.

17. Ong ST, Koeppen H, Larson RA, Olopade OI. Successful treatment of angioimmunoblastic lymphadenopathy with dysproteinemia with fludarabine. Blood 1996;88:2354-5.

18. Tsatalas C, Margaritis D, Pantelidou D, Spanudakis E, Kaloutsi V, Bourikas G. Treatment of angioimmunoblastic lymphadenopathy with dysproteinemia-type T-cell lymphoma with fludarabine. Acta Haematol 2003;109:110.

19. Schetelig J, Fetscher S, Reichle A, et al. Long-term disease-free survival in patients with angioimmunoblastic T-cell lymphoma after high-dose chemotherapy and autologous stem cell transplantation. Haematologica 2003;88:1272-8.

20. A predictive model for aggressive non-Hodgkin's lymphoma. The International Non-Hodgkin's Lymphoma Prognostic Factors Project. N Engl J Med 1993;329:987-94.

21. Rodriguez J, Cabanillas F, McLaughlin P, et al. A proposal for a simple staging system for intermediate grade lymphoma and immunoblastic lymphoma based on the 'tumor score'. Ann Oncol 1992;3:711-7.

22. Gallamini A, Stelitano C, Calvi R, et al. Peripheral T-cell lymphoma unspecified (PTCL-U): a new prognostic model from a retrospective multicentric clinical study. Blood 2004;103:2474-9.

23. Rodriguez J, Caballero D, Gutierrez A, et al. Long-term follow-up of autologous stem cell transplantation (ASCT) in patients with peripheral T-cell lymphoma (PTCL): the Spanish Lymphoma Cooperative Group (GEL-TAMO) experience. Ann Oncol 2005;16:v56.

24. Cheson BD, Horning SJ, Coiffier B, et al. Report of an international workshop to standardize response criteria 
for non-Hodgkin's lymphomas. NCI Sponsored International Working Group. J Clin Oncol 1999;17:1244.

25. Kaplan E, Meier P. Nonparametric estimation from incomplete observations. J Am Stat Assoc 1958;53:457-81.

26. Peto R, Pike MC, Armitage $\mathrm{P}$, et al. Design and analysis of randomized clinical trials requiring prolonged observation of each patient. II. analysis and examples. $\mathrm{Br} J$ Cancer 1977;35:1-39.

27. Armitage JO, Vose JM, Linder J, et al. Clinical significance of immunophenotype in diffuse aggressive nonHodgkin's lymphoma. J Clin Oncol 1989;7:1783-90.

28. Coiffier B, Brousse N, Peuchmaur M, et al. Peripheral T-cell lymphomas have a worse prognosis than B-cell lymphomas: a prospective study of 361 immunophenotyped patients treated with the LNH- 84 regimen. The GELA (Groupe d'Etude des Lymphomes Agressives). Ann Oncol 1990;1:45-50.
29. Melnyk A, Rodriguez A, Pugh WC, Cabannillas F. Evaluation of the Revised European-American Lymphoma classification confirms the clinical relevance of immunophenotype in 560 cases of aggressive non-Hodgkin's lymphoma. Blood 1997;89:4514-20.

30. Strupp C, Aivado M, Germing U, Gattermann N, Haas R. Angioimmunoblastic lymphadenopathy (AILD) may respond to thalidomide treatment: two case reports. Leuk Lymphoma 2002;43:133-7.

31. Joly B, Frenkel V, Gaulard P, et al. Rituximab in combination with CHOP regimen in angioimmunoblastic T-cell lymphoma (AITL). Preliminary results in 9 patients treated in a single institution. Blood 2005;106:2686.

32. Halene S, Zieske A, Berliner N. Sustained remission from angioimmunoblastic T-cell lymphoma induced by alemtuzumab. Nat Clin Pract Oncol 2006;3:165-8. quiz 169. 